$\begin{array}{llllllllllll}R & T & I & C & U & L & O\end{array}$

$D E R E F L E X I O ́ N$

\section{"Pisándole la cola al diablo" MUJERES Y HOMBRES HOMOSEXUALES QUE DESEAN PERMANECER EN LA IGLESIA CATÓLICA}

\author{
"PISÁNDOLE LA COLA AL DIABLO" GAY MEN AND WOMEN WHO \\ WISH TO STAY IN THE CATHOLIC CHURCH
}

Por: Alfonso Gómez Rossi.

Recibido 11 de junio de 2013. Aprobado 15 noviembre 2013.

Universidad de las Américas de Puebla, México. PhD. Creation and Culture Theories, . Profesor en el "Instituto Universitario Boulanyer"

\section{RESUMEN}

Desde tiempo atrás, la iglesia católica es uno de los grupos ideológicos, que más oposición ha generado al reconocimiento de "derechos especiales", para los hombres y mujeres de la comunidad LGBT en Norteamérica. Esta ha sostenido históricamente una postura conservadora y a pesar de ello en las últimas décadas del siglo XX, se observan segmentos de la población homosexual, que aun ante esto, deciden permanecer en la institución, con el interés de hallar equilibrio entre sus ideales espirituales y su sexualidad, lo cual se contrapone al dogma católico. Este articulo analiza las ideas que formaron la relación entre el catolicismo y la comunidad lésbico-gay, a partir de postulados de Agustín de Hipona y Tomás de Aquino, quienes exploraron a través de sus textos las nociones de libre albedrío y lo natural, ideas que tienen un rol determinante en la relación conflictiva de ambos grupos. El artículo explora algunos postulados del grupo "Courage" movimiento en torno a valoraciones antagónicas para la comunidad LGBT.

Palabras claves: Courage, gay, homosexualidad, iglesia católica, libre albedrío, tomismo, Norteamérica.

\begin{abstract}
:
The Roman Catholic Church has been an ideological bastion that has fought against the recognition of 'special rights' for men and women who identify themselves as a part of the LGBT community in the three North American countries. Despite the fierce opposition from the Church against the advancement of 'gay rights' and the resentment it causes, it is surprising to discover that there are gays and lesbians who have chosen to remain within the institution, trying to bridge the ideals of both groups by negotiating their actions and beliefs. This article analyzes the ideas that established the tense relationship between the Catholic Church and the LGBT community by exploring the ideals of St. Augustine and St. Thomas Aquinas who were indirectly responsible through the interpretation of scripture and Greek philosophy for the ways Catholicism views the LGBT movement; the piece also explores the Catholic group "Courage" and its beliefs about homosexuality, which seem to support what Augustine and Thomas wrote.
\end{abstract}

Keywords: Homosexual, gay, tomism, Courage, libre albedrío, Norteamérica. 


\section{Introducción}

$\mathrm{E}$ xiste una tradicional confrontación ideológica entre la jerarquía católica y los miembros del movimiento LGBT ${ }^{1}$, acerca de las decisiones tomadas por los segundos, en torno a su sexualidad; la polémica que más involucra a ambos grupos, indica que los hombres y las mujeres identificados por sí mismos, como gays y lesbianas, no son bienvenidos en la institución católica debido a su identidad, sexualidad y estilo de vida, los cuales tienden a confrontar algunos principios de la Iglesia. Sin embargo, es sorprendente descubrir que a pesar del rechazo sistemático e incluso de la discriminación que padecen por parte de la institución, hay segmentos de la población lésbico-gay en los tres países del norte (México, Canadá y Estados Unidos) que están dispuestos a permanecer en la institución católica, negociando así sus acciones en la vida cotidiana, su ideología y estilo de vida, a pesar de las contradicciones que surgen entre dos puntos de vista que son profundamente divergentes ${ }^{2}$. Thomas C. Fox (1995) escribe: "una vez que se es Católico siempre se es Católico. Muchos gays y lesbianas que odian el rol homofóbico que ha tenido la Iglesia, aun buscan dentro de la misma una guía y un sentido espiritual (p. 131). ${ }^{3 \prime}$

La tensión entre ambos grupos en los tres países (México, Canadá y Estados Unidos) que aquí se estudian, se puede verificar en varias fuentes, artículos de periódico o revistas, las cuales escriben a favor o en contra de las posturas de cada grupo ${ }^{4}$, del mismo modo a través de la experiencia personal de hombres y mujeres, que han escuchado a algunos religiosos manifestarse en contra de las acciones homosexuales en diversos contextos sociales. El rechazo que experimentan de la institución religiosa, queda ejemplificado en las acciones tomadas por un grupo de homosexuales católicos, los cuales han escogido utilizar la fajilla con los colores del arcoíris para escuchar misa y comulgar. La pieza de tela multicolor, provocó la ira de algunos jerarcas, al verla como una demostración de antagonismo hacia la institución católica; para ilustrar lo anterior, el almanaque católico del 2006 editado por Mathew E. Bunson (2005) describe brevemente la reacción de un alto jerarca, en torno al uso de la fajilla multicolor:

El Cardenal Francis Arizne, declaró el 4 de febrero [del 2005] que las personas que usaran la fajilla con los colores del arcoíris, se descalificaban así mismos de recibir la Santa Comunión, porque la prenda de ropa, simboliza su oposición a las enseñanzas católicas sobre la homosexualidad (p. 25) ${ }^{5}$.

1El acrónimo LGBT
significa lésbico, gay,
bisexual y transgenero.
Cuando se utilice en este
trabajo incluye a los
miembros que se iden-
tifican como parte de la
"comunidad gay."
2Existen movimientos en
los tres países identifica-
dos en el texto, que bus-
can modificar la relación
entre la comunidad LGBT
y la iglesia Católica. John
Cornwell escribe en su
libro Breaking Faith:
"'There are growing
numbers of highly or-
ganized Catholic and
ecumenical homosexual
networks in the world
today. They have their
own chaplains, websites,
newsletters and liturgies.
They are telling Rome
and their Bishops that
whatever the Church's
teaching, they want
to belong. "The leading
groups include in the
United States, Dignity,
Conference for Catholic
Lesbians, Courage, New
Ways Ministry (the net-
work established by the
silenced religious Father
Robert Nugent and Sister
Jeannine Gramick), in
Mexico Otras Ovejas"
(Cornwell 2001 p. 128)

3[Traducción del autor
del presente textol
4A favor de una relación
positiva entre el catolicis-
mo y la comunidad gay
se encuentran autores
como Daniel Helminiak,
Mark D. Jordan, John
Boswell, y Eugene Ken-
nedy entre otros; en con-
tra de cualquier tipo de
relación armónica entre
el movimiento LGBT y
el catolicismo destacan
autores como, Benedict
Groeschel así como S.S.
los Papas Juan Pablo II y
Benedicto XVI.

${ }^{5}[$ Del autor del presente texto. 
${ }^{6}$ El sitio del grupo es: http://www.dignityusa.org

${ }^{7}$ El sitio del grupo es: http://www.dignitycanada.org/

${ }^{8}$ El sitio del grupo es: http://www.newwaysministry.org/
Estas ideas demuestran que existen dos representaciones culturales del mismo problema: en primer lugar, un grupo de personas de la comunidad LGBT, que desean participar del sacramento de la comunión y a su vez mostrar que se sienten orgullosos de pertenecer al movimiento gay, usando la fajilla multicolor que simboliza a dicha comunidad, y en segundo lugar, una jerarquía religiosa, la cual toma como afrenta el hecho de que estas personas por sus orientaciones sexuales han sido repudiadas en el pasado y en el presente por la misma iglesia; no obstante, que hoy en día un fragmento de los miembros de la iglesia se inclinen hacia una nueva comprensión del tema y asimismo se atrevan a mostrar una alianza que en últimas implica en parte, aceptación de los homosexuales que profesan la fe católica, es ya un nuevo antecedente del problema. A su vez, es un hecho que se puede entender como una postura mediadora entre los diversos intereses, pues una iglesia excluyente y tradicional ha marcado por muchos siglos la segregación.

Complementando lo anterior, la iglesia católica adopta la máxima de Cristo en el evangelio de Mateo, que afirma "Nadie puede servir a dos señores; porque o aborrecerá a uno y amará al otro, o se apegará a uno y despreciará al otro" (6:24); si los hombres y mujeres que tienen preferencias homo-eróticas les interesará permanecer en comunión con Roma, la elección que deben tomar es permanecer invisibles dentro de la misma institución, no pudiendo diferenciarse de otros seglares ya que de hacerlo sus decisiones los pueden excluir de la comunidad católica.

Otro hecho sorprendente el cual resulta de gran interés, son estas apreciaciones: Anthony Gill (1998) escribe que durante la modernidad se asumió, que la religión iría desapareciendo de la vida pública e incluso privada, de acuerdo a la teoría de la secularización (p. 3) y bien como describe Mark D. Jordan (2000) aún existen hombres y mujeres homosexuales que desean permanecer en la institución católica de la que hacen parte en virtud del bautismo (p. 2), a pesar de que pueden escoger abandonar una iglesia que oficialmente no está de acuerdo con su estilo de vida. Esta afirmación resalta otro hecho, y es que existe en Norteamérica una dinámica religiosa un tanto distinta a la del resto de los países del centro; Juan Carlos Herrero (2001) afirma en su libro La sociedad gay, que: es en América del Norte, donde existen grupos como Dignity USA $^{6}$ o Dignity Canada Dignité 7 así como The new ways minsitry ${ }^{8}$, que han intentado reconciliar al movimiento LGBT con la teología cristiana (p. 190). Los grupos ya mencionados, creen que sus miembros pueden ser católicos y asimismo parte de la comunidad LGBT, percepción que los ha llevado a crear 
organizaciones que tratan de reconciliar ideales del movimiento gay con las creencias católicas, participando dentro de los sacramentos que la iglesia le permite a cualquiera de sus miembros, pero se topan con una jerarquía segura de que ser católico es incompatible con los ideales de la comunidad gay. Estos argumentos excluyentes conviven también con la doble moral norteamericana, que critican en público lo que practican en privado, pues es muy reconocido el tema de sacerdotes homosexuales a la sombra de la iglesia, de sacerdotes con hijos y de otros que desearían casarse con una pareja heterosexual con la que han sostenido una larga relación, logro que ya ha alcanzado la iglesia anglicana y la episcopal.

Por otro lado el tema de homosexualidad y catolicismo, ha sido analizado por varios autores de distintas disciplinas, como historiadores, teólogos, filósofos, entre otros; que han adoptado dos posturas opuestas: una postura, trata de reconciliar a la homosexualidad y al catolicismo con la finalidad de hacerlos miembros por derecho propio a la institución, mientras que el otro grupo, observa que las diferencias entre ambos son irreconciliables y por lo tanto incompatibles ${ }^{9}$. Las diferencias entre ambos grupos han sido analizadas particularmente desde el estudio de los evangelios, como lo demuestra Daniel Helminiak en su libro What the bible really says about homosexuality (1995) o Raúl Lugo en su texto Iglesia Católica y homosexualidad (sin fecha), este trabajo propone, que para comprender el rechazo a las acciones homosexuales, tiene relevancia el estudio de cómo se fortaleció dentro de la religión católica el concepto de libre albedrío ${ }^{10}$ y la idea de lo que es natural en las relaciones sexuales. A partir de un breve resumen del debate sobre la libertad de escoger, importante para comprender las relaciones entre ambos grupos, se analizará un movimiento que se formó en torno a la relaciones entre comunidad LGBT y la institución católica en los países norteamericanos.

Es evidente que la iglesia Católica norteamericana ${ }^{11}$, no ha permanecido estática al discurrir de la historia, aun cuando los cambios de mentalidades han sido lentos; los motivos utilizados por la jerarquía católica, para rechazar las acciones homosexuales, están basados en ideas las cuales serán modificadas a la luz de los descubrimientos realizados en las ciencias naturales, así como a través de hallazgos arqueológicos e históricos, los cuales proponen nuevas formas de interpretar la información y a su vez puede ser calificada de cuestionable en torno a la homosexualidad. Este último argumento parece fantástico cuando se contemplan los hechos en torno al catolicismo, una institución cuya renuencia a aceptar el cambio se demuestra en la historia
${ }^{9}$ Entre los que se destacan John Boswell, Matthew Jordan Dan Helminiak o Raúl Lugo en el espectro liberal, mientras que entre los conservadores se encuentran los Papas uan Pablo II y Benedicto XVI.

${ }^{10 “} \mathrm{El}$ 'Libre albedrío' es un término filosófico... para un tipo particula de capacidad que tienen los agentes racionales de escoger una acción entre distintas alternativas. La mayoría de los filósofos suponen que el concepto de libre albedrío esta cercanamente conectada al concepto de responsabilidad moral Actuando con la libertad de escoger desde esta perspectiva desde esta perspectiva, es justo para satisfacer los ser responsable de las cer responsable de las acciones de uno. La relación entre libre albedrío no se nexión con en de bilion con la responsailidad moral. La hibertad de escoger se relaciona con la autonomía y la dignidad de las perso "libre albedrio" Stanford "libre albedrio" Stanford sophy [7 Ene. 2002 (Mar. 3 2012)] disponible en: http://plato.stanford edu/entries/freewill/

${ }^{11}$ Entendida en el contexto de este articulo como la unión geográfica de México, Canadá y Estados Unidos. 
En México fue notorio el caso de Marcial Maciel undador de la Legión de Cristo, acusado no solo de haber tenido hijos con dos mujeres distintas durante lar niños $y$, ar ninos y adolescentes así como de abusar de las drogas ver a forres Robles, "La prodigiosa rent ". ios de Cristo". En Estado Unidos está el caso, de Cardenal Mahoney en Los Ángeles que también protegió al padre mexicano Nicolás Aguilar, entre otros en Manto Purpura de San Juana Martínez. Para ver los distintos casos de abuso sexual de parte de autoridades 0 burocracias eclesiales ver el sitio de SNAP (Survivors Network of Those Abused by Priests): www. snapnetwork.org

${ }^{13}$ En el sitio The International Sexual Abuse Monitor aparecen las noticias más recientes de abuso sexual de menores en "Estados Unidos, Canadá Alemania, Austria, Suiza, Italia, España, Bélgica, Holanda, Reino Unido, Irlanda y más" ver el sitio en: http://WwW.verschueren.at/International sexual abuse newsmonitor.html moderna, a partir del juicio que se instituyó contra Galileo Galilei (15641642) que con sus descubrimientos científicos contradijo los ideales católicos (Kauffman 1999 p. 24).

Este artículo se estructura en torno a la noción, corroborada en diversos textos históricos, de que la institución religiosa si se ha transformado y estos cambios le han posibilitado retener la devoción de sus feligreses. El cambio que se puede observar dentro de la institución católica se ejemplifica en la actitud que operó en la institución hacia el pueblo judío al discurrir el siglo XX, y particularmente, como afirma Mathew Bunson (2005) a partir del Concilio Vaticano II (p. 260), al grado que nos narra James Carroll (2002) que S.S. Juan Pablo II emitió una disculpa por los errores que tuvo la institución católica hacia la comunidad judía (p. 553).

La iglesia Católica está pasando por momentos de crisis que algunas personas como Jason Berry y David Gibson han escrito que es grave, comparable a los movimientos de la Reforma Protestante del siglo XVI; la crisis fue notoria durante la primera década del siglo XXI, debido al escándalo social que envolvió a varios sacerdotes católicos en Estados Unidos y México ${ }^{12}$ que fueron acusados de pedofilia y efebófilia (Bunson 2005 p. 82); la indignación justificada de una sociedad que cuestionaba las decisiones de una minoría de sacerdotes, que pregonaban la abstinencia sexual o la gratificación sexual con fines no reproductivos y que en las sombras abusaban de su poder con menores de edad, dejó en su estela un problema de relaciones públicas con su feligresía, que se han ido resolviendo de manera gradual, según la racionalidad en la que se infiere que el dogma y las creencias son perfectos e incuestionables, los seres humanos no, una gran falacia ante la interpretación de las ciencias sociales, pues este tipo de argumentos dogmáticos se halla al margen de los derechos humanos y de la justicia.

El escándalo de la pedofilia en Estados Unidos, Austria, México, Irlanda y Canadá ${ }^{13}$ es relevante en diferentes contextos políticos, por la reacción que tuvo El Vaticano en el manejo del asunto: El 23 de abril del 2002, S.S. Juan Pablo II, sostuvo una junta con arzobispos y obispos estadounidenses, para reflexionar y discutir sobre el abuso sexual que padecieron niños y adolescentes de ambos géneros en los Estados Unidos. De acuerdo con Carlos Fazio (2004) en la junta "el Papa exigió "cero tolerancia" para los sacerdotes pedófilos. Ante un número reducido de representantes eclesiásticos de los Estados Unidos, Juan Pablo II calificó los abusos cometidos contra los infantes como un "crimen" 
y "un pecado terrible ante los ojos de Dios"; les advirtió que no había lugar en el sacerdocio o la vida religiosa para aquellos que les hicieran daño a los jóvenes. De acuerdo al pontífice, la Iglesia necesitaba pasar por un proceso de purificación" (p. 20) y para lograrlo era necesario desterrar del ministerio a los homosexuales que estaban ejerciendo el ministerio de sacerdotes y hermanos religiosos dentro de la institución católica (p. 21-2). Eran los homosexuales en la visión papal e institucional, no los pedófilos, los responsables del abuso de los menores de edad en la nación norteamericana.

El remedio que se instituyó, fue la exclusión de la ordenación religiosa de aquellos individuos con preferencias homosexuales, ya que se les consideraba predadores sexuales (Berry 2004 p. 29-30), acciones que promueven la discriminación de una minoría sexual, que ha sido excluida fuertemente en el pasado y en el presente. Lo que aún no queda claro es la distancia que los jerarcas católicos comprenden entre pedofilia y homosexualidad sea real, puesto que la primera no es consecuencia de la segunda, son temas distintos, ya que un concepto no es sinónimo del otro y asimismo continúa siendo cuestionable este argumento, como la no aceptación de las personas que se identifican como gays y lesbianas, por parte de una de las instituciones cristianas más numerosas del mundo. Alcanzar esta aceptación de parte de la iglesia se convertiría en un hecho afirmativo para la institución religiosa y una manera de paliar la discriminación en contra de los homosexuales católicos que existe en varias regiones del mundo.

Parafraseando a Charles Kaiser (1997), la creencia generalizada que las relaciones sexuales entre personas del mismo género son pecaminosas, ha sido responsable en parte por la discriminación que aún se evidencia en forma legal en las diversos países americanos (p. ix). Lo importante aquí, es explorar los temas sobre los que gira el debate: la primera parte del texto muestra las ideas que originaron parte del conflicto al hacer un recuento histórico breve de las enseñanzas católicas, la segunda analiza que grupos han creado los homosexuales identificados con el catolicismo, para permanecer dentro de la comunidad católica. Y las contradicciones entre ideología católica y homosexualidad, en particular cuando los homosexuales son los feligreses y no los miembros de la jerarquía religiosa. 
${ }^{14}$ [Mi traducción del autor del presente texto] En este punto es interesante insertar la frase de Michel Foucault sobre lo normal, ya que se aplica a la relación entre homosexualidad y catolicismo: “...if you are not like everybody else, then you are abnormal, if you are abnormal, then you are sick. The se three categories, not being like everybody else, not being normal and being sick are in fact very different but have been reduced to the same thing." En su obra Disciplina ciplina y castigo (1977) Fucault establece que l pror ser huma implica dening que es normal, saludable y deseable. En deseable se define bién lo que es anormal.

\section{El debate construccionista-esencialista y la importancia que tiene para la inclusión/exclusión de la comunidad gay.}

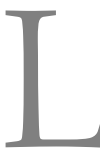

os autores que se han especializado en el área de estudios queer, están divididos en dos concepciones sobre lo que origina la homosexualidad; el debate es importante en el contexto cultural, porque nos permite entender las batallas que libra el cuerpo con relación al bio-poder establecido; este término usado por Foucault (1978) presenta la propuesta que este tipo de poderes atraviesa la psiquis, el cuerpo y los aprendizajes del yo, en un contexto en que las instituciones, fijan una permanencia de la sexualidad en lo aparentemente normal y al interior de estas estrategias de dominación subjetiva del pensamiento social, se establecen dominaciones que transcurren a lo largo de la historia, señalando que las dinámicas culturales difieren de las normas inventadas para delimitar la libertad del cuerpo.

El énfasis sobre el tema de la libertad que tienen los individuos, al escoger entre sus creencias y sus deseos no es de importancia para la iglesia católica, por otra parte, la homosexualidad es considerada una construcción social. De acuerdo a John J. McNeill (1988) los católicos conservadores creen que "el homosexual es una persona en conflicto porque lo entienden como un heterosexual que escoge preferir a personas de su mismo sexo, o una persona con algún tipo de enfermedad mental (p. xix) ${ }^{14 \prime \prime}$; los gays y lesbianas católicas por otro lado prefieren creer que es una preferencia natural parte de su esencia y que existe en ellos desde el momento en que nacieron.

Raúl Lugo sostiene que estos puntos de vista opuestos son utilizados en términos teológicos y filosóficos como razón y argumento, para determinar si los homosexuales están cometiendo un pecado, cuándo están involucrados en una relación sexual con sus parejas u otros individuos, argumento que determina si los gays y lesbianas pueden ser salvados o no (p. 12). El debate contemporáneo, es en realidad parte de una discusión histórica que ocurre en el catolicismo desde el siglo V sobre el rol que tiene el libre albedrío y la predestinación en la cosmovisión católica.

Una de las creencias fundamentales que se viene promoviendo es que los hombres gays y las mujeres lesbianas, que quieren ser aceptados por la institución católica deben encontrar en la teología y tradición católica diversas maneras de justificar su estilo de vida. Un ejemplo claro de ello fue la labor que realizó el historiador John Boswell en su obra Christianity, social tolerance and homosexuality (1980) intentando demostrar que el cristianismo 
no fue originalmente antagónico hacia las conductas y relaciones homoeróticas, y que al no serlo en ciertas épocas del medioevo (476 d.C-1453 d.C.) particularmente en la Alta Edad Media, no tendría por qué serlo en la época moderna; con este planteamiento la mayoría de las iglesias cristianas podrían incorporar a la comunidad gay dentro de su rebaño (Kueffler 2006 p. 2). De acuerdo a Mathew Kueffler (2006) el texto de Boswell generó un debate que continúa hasta hoy sobre el uso que le dio a la palabra 'gay' para describir todo tipo de conductas que abarcaban homosexualidad, la homo-sociabilidad y la bisexualidad y que para sus detractores le restó mérito a un trabajo que usaba la palabra 'gay' fuera del contexto histórico del que se escribía (p. 9).

Otra forma de encontrar un espacio para los gays y lesbianas, dentro del catolicismo es a través de la búsqueda de la formación de las ideas al interior de la tradición filosófica de la Iglesia, que está inspirada en gran medida por las escuelas filosóficas de Platón y Aristóteles, representados por los dos intelectuales del catolicismo que abrazaron los ideales de cada filósofo: San Agustín de Hipona que utilizó a Platón, mientras Gardeil (1973) explica que Santo Tomás de Aquino se inspiró en Aristóteles (p. 15). Cornwell (2001) y Boswell (1980) afirman que ambos santos interpretan la doctrina Cristiana reflejada en los Evangelios utilizando un sistema de creencias de filósofos de la Grecia Antigua; los dos aseguraban que existía una "ley natural" (p. 19 y p. 150 respectivamente), concepto relevante para los homosexuales, ya que está creencia en leyes naturales tenía la finalidad de reforzar lo que afirmaban los Evangelios y explica por qué la iglesia católica considera que algunas acciones sexuales son permisibles, mientras que otras son condenadas. Ambas filosofías, tomismo y agustinianismo, tienen elementos que pueden ser incluyentes en torno a los homosexuales, aunque de acuerdo a John J. McNeill (1988) ambos santos creían que las acciones homo-genitales eran pecaminosas (p. 95-6). Como se verá con relación a los conceptos de libre albedrío y como es natural son parte integral del debate actual.

San Agustín de acuerdo con Thomas F. Martin (2003), fue el creador del concepto de libre albedrío, así como el de predestinación y a su vez también fue responsable de su inserción en la doctrina cristiana, que surgió a partir de la pregunta que se formuló Agustín "nuestra salvación ise logra por la gracia de Dios o por nuestras acciones? (p. 37) ${ }^{15 "}$. La respuesta de acuerdo a Paul B. Clark y Emma Norman (1998) varió con la edad del Santo originario de Tagaste: "Agustín inicialmente mantuvo que la voluntad era un poder antropológico efectivo en una gran cantidad de acciones, sin importar cuál 
${ }^{16}$ [Traducción del autor del presente textol

${ }^{17}$ [Traducción del autor del presente texto]

${ }^{18}$ [Traducción del autor del presente texto]

${ }^{19}$ Para una definición breve de gracia leer a p.143.

20 [Traducción del autor del presente texto] era el estatus moral de estas. Posteriormente concluyó que para los seres humanos solo es posible escoger la maldad, ya que lo bueno pertenecía a la gracia de Dios y no a las acciones de los humanos (p. 2) ${ }^{16}$." Agustín en sus años mozos escribió sobre el mal y su conclusión de acuerdo a Clark y Norman, es que el mal no provenía de Dios, que solo podía ser la fuente del bien, y desarrolló la idea que "los humanos poseen la capacidad de iniciar acciones que no estaban causadas o predeterminadas por Dios (p. 2) ${ }^{17}$." La creencia que los seres humanos tienen de libre albedrío, piedra fundamental de las creencias católicas de acuerdo a Mathew E. Bunson (p. 142) y el Catecismo de la Iglesia Católica (2000), aún es importante para la tradición católica y la diferencia de otros grupos cristianos, particularmente de aquellos discípulos de Juan Calvino que creen en la predestinación (Martin p. 128). El católico participa del sacramento de la confesión para explicar por qué ha pecado de acuerdo a la libertad que le dio Dios de escoger entre el bien y el mal; los individuos homosexuales en esta concepción escogen actuar erróneamente, ya que Dios le dio la facultad de escoger la conducta que consideran apropiada.

San Agustín cambió de opinión sobre libre albedrío en su vejez. Clarke y Norman escriben: "En su carta al Papa Sixto III, Agustín insistió que los humanos eran completamente dependientes de la gracia de Dios y no podían aspirar a ser buenos sin la gracia (p. 5) ${ }^{18}$." Esta creencia de San Agustín lo confrontó con los pelagianos, grupo cristiano que estaba de acuerdo con los postulados que San Agustín escribió en su juventud sobre el libre albedrío; su pensamiento generó controversia, tanto que el movimiento encabezado por Pelayo fue considerado una herejía. Los postulados del grupo versaban en torno al libre albedrío y la gracia ${ }^{19}$, lo que desató una confrontación ideológica conocida en la historia como "la herejía pelagiana". Al centro del debate estaba Agustín, quien afirmaba haber estado equivocado en sus años mozos y que: "el bien es un regalo divino incondicional, y no es una facultad gratuita. Por lo tanto escoger el bien no conduce a la gracia de Dios... San Agustín (...) introdujo entonces la teoría de la predestinación... Dios existía afuera del tiempo y es eterno, por lo tanto contemplaba el fin del tiempo desde el principio ${ }^{20 \prime}$ (Clarke 1998 p. 6-7).

En el siglo XIII otro santo modificaría algunas de las creencias que el catolicismo había tenido hasta ese momento al incorporar las ideas de Aristóteles al cristianismo Occidental: el dominico Tomás de Aquino (12251274), creía que para entender como operaba el mundo y como debían comportarse hombres y mujeres, el individuo podía buscar fuera de La Biblia 
la manera en que cambiaba naturalmente el mundo, a partir de la conducta de los animales para comprender que era lo que Dios esperaba de su creación (Boswell 1980 p. 319). La creencia que Dios ha pre-ordenado una manera natural, es positiva para el hombre, tenía su contraparte en la noción de que había acciones que iban contra la naturaleza que perdura hasta nuestros días. El Aquinate "fue el único [filósofo] escolástico de renombre, que discutió las prácticas homosexuales en detalle (McNeill 1988 p. 95) 21", pero la manera en que trató las acciones homo-eróticas, debe ser contextualizada en el tiempo que escribió lo que significa que algunos informes o conocimientos que poseía eran erróneos o no confiables. Como demuestran John Boswell (1980), Luján (2003) y McNeill (1988) lo que las personas creían en ese momento podía ser fantástico de acuerdo a nuestras creencias actuales (Luján 2003 p. 56). Santo Tomás reconoció las limitaciones con las que se encuentra un investigador en cualquier momento de la historia y decía que es imposible conocer toda la verdad en la vida (Audi 1996 p. 31), dejándole a sus futuros discípulos la opción de corregir algunas de sus afirmaciones (McNeill 1988 p.96).

La escuela tomista (Audi 1996 p. 800-1) fue debatida durante siglos después de su deceso, como lo señala Bertrand Russell (1959), por los seguidores de San Agustín que continuaban creyendo y enseñando las ideas agustinianoplatónicas que habían imperado desde el siglo V (p. 156, 160). Santo Tomás aplicó una combinación de racionalismo y teoría sobre las leyes naturales para justificar y defender las creencias cristianas utilizando lo que ocurre más allá de los Evangelios.

El hecho que el catolicismo adoptase al tomismo como una manera de entender cómo funciona el mundo puede ayudar a comprender la homosexualidad (p. 157), si, como propone Fausto Sterling (2000), se llegara a aceptar que la homosexualidad, es una ocurrencia biológica natural (p. 26), instituida por Dios, y por tanto restándole la acción de pecado porque es natural. Este argumento fue el que usó El Vaticano para justificar que la homosexualidad no es un pecado por sí misma, como lo demuestran los documentos que ha expedido El Vaticano sobre el tema y que cita Juan Carlos Herrero Brasas (2001 p. 190), lo que lo convierte en pecado, es el contacto genital y el goce que de ello se deriva lo que distancia a los gays y lesbianas de la institución católica.

Demostrar que la homosexualidad es genética o producto de algún proceso natural del cuerpo no es suficiente para la Iglesia, que arguye que la persona debe vivir una vida casta (Herrero Brasas 2001 p. 190); para ser aceptados 
${ }^{22}$ El caso más conocido de
violencia en contra de las violencia en contra de las cias homosexuales fue e caso del estadounidense Matthew Shepard, aseSu asesinato fue influyente en la discusión sobre aprobar leves contra de los crímenes de odio en Estados Unidos. Ver: (Matthews Place 2013 http://www.matthewsplace.com/) por la Iglesia los homosexuales pueden abrazar un argumento esencialista que justifique que Dios los creó así (Fausto-Sterling 2000 p.144). El argumento puede toparse con dificultades si se demuestra que las preferencias homoeróticas no son genéticas y que son adquiridas después del nacimiento, ya que la Iglesia Católica podría afirmar que son una construcción debida a traumas de la infancia y a la exposición a una cultura urbana hedonista que busca solamente el placer (Eribon 1999 p.: 34). El debate parece no tener una solución satisfactoria para la comunidad LGBT que aún enfrenta discriminación cuando se usan términos que los encasillan en lo anormal.

Mientras que el debate sobre la construcción o la esencia de la homosexualidad continúa, la comunidad LGBT necesita protección de grupos radicales que utilizan argumentos basados en la teología para discriminarlos. Los crímenes de odio en los países norteamericanos han sido comunes en el pasado y la justificación de la violencia en contra de los homosexuales se puede encontrar en muchas ocasiones en las creencias religiosas del agresor ${ }^{22}$. A pesar de la adversidad con la que se enfrentan los homosexuales vis a vis la iglesia católica, es interesante destacar que existen organizaciones que tratan de reconciliar a los grupos LGBT con la institución, aunque esto se hace de diversas maneras como se explorará en el siguiente apartado.

Los individuos con preferencias homosexuales que han sido bautizados son técnicamente parte del cuerpo místico de Cristo, a pesar de sus acciones pecaminosas, y se enfrentan a varias opciones, entre las que está dejar a la iglesia completamente para creer en cualquier religión, no creer en nada o buscar opciones espirituales en otras religiones o filosofías. Aquellas personas que deciden permanecer dentro de la iglesia se topan con el rechazo de la jerarquía católica, asimismo la iglesia no está conformada solamente por sacerdotes, monjas y hermanos o hermanas religiosas seculares y regulares de los distintos países del mundo, sino que el catolicismo está formado por todas aquellas personas que están bautizados y que en la comunidad de fieles o seglares se encuentran opiniones divergentes de lo que dice la doctrina oficial de El Vaticano.

Son los seglares, que constituyen el grueso de la iglesia, los que pueden efectuar transformaciones o cambios que modifiquen ciertas conductas o creencias, dentro de los límites de la ortodoxia cristiana; esta idea no es novedosa y algunos intelectuales como Boswell o Norman afirman que una de las claves del éxito de la religión cristiana ha sido la capacidad que ha tenido para 
adaptarse a los cambios de las distintas épocas que han pasado en el transcurso de dos milenios, adoptando nuevas maneras de pensar que la han ayudado a interpretar las circunstancias cambiantes. Esta flexibilidad se observa incluso en la actualidad, cuando la Congregación de la Doctrina de la Fe invitó a través de la prensa a aquellos anglicanos o episcopales que no estuvieran de acuerdo con la ordenación de mujeres o los homosexuales a cambiarse al catolicismo que estaba doctrinalmente más cercana a sus creencias que la "liberal" iglesia anglicana (Donadio 2009: http://www.nytimes.com/2009/10/21/ world/europe/21pope.html), cita en la bibliografía. Uno de los obstáculos que parecía ser inquebrantable para los anglicanos que deseaban cambiar su filiación era la aceptación de aquellos ministros anglicanos casados que quisieran convertirse en sacerdotes, hecho que no ha tenido relevancia y ha sido sorteado a través del reconocimiento de los antiguos ministros que ahora son sacerdotes y pueden permanecer casados adaptándose a los rituales de las iglesias católicas orientales. (Tavis 2009: http://cnsblog.worldpress. com/2009/10/31/clarification-on-anglicans-and-married-priests/).

El debate demuestra que la iglesia está dispuesta a aceptar el cambio, de manera gradual e imperceptible para los feligreses que lo viven en un espacio y época determinada, no obstante los conflictos ideológicos y teleológicos. La historia antes mencionada revela también que la iglesia reconoce que puede haber cierta debilidad si aparece demasiado arcaica y que la mueve a flexibilizarse para atraer más adeptos. La necesidad de la iglesia católica de acomodarse frente a los signos de una época, puede interpretarse como que la opinión de sus seglares importa y significa que los católicos de manera individual o comunitaria pueden darle forma a ciertos ideales de la iglesia que pueden parecer extremos (McNeill 1988 p. xix).

Como quedó asentado en líneas anteriores, una de las opciones que tienen las personas con preferencias homosexuales es abandonar la iglesia si sus opiniones van en contra de las opiniones generalizadas del clero (Johnson p. 132-3) y algunos jerarcas así como seglares preferirán que los homosexuales abandonaran la institución ("Should liberals leave the Catholic Church? 2006: http://www.boston.com/news/globe/editorial_opinion/oped/ articles2006/03/05/should_liberals_leave_catholic_church/), lo que mueve al lector a reflexionar sobre lo que se está pidiendo.

Se pueden destacar dos puntos sobre la respuesta al argumento que la comunidad lésbico-gay debe abandonar la iglesia: el primero es que la iglesia 
está dispuesta a negociar la entrada o salida de personas que no necesariamente están completamente de acuerdo con el dogma institucional, con la intención de incrementar el rebaño y preservar así a la ideología para futuras generaciones. Esta estrategia que podríamos llamar 'flexibilidad institucional' o simplemente oportunismo, parece darle un matiz de inconsistencia a la iglesia que resulta chocante para la comunidad LGBT, que no cumple los preceptos de la iglesia "al pie de la letra."

El segundo punto que se destaca es que, si los homosexuales quieren efectuar un cambio a la institución católica y creen en varios de sus preceptos o sienten que de algún modo enriquece su vida, lo último que deben hacer es dejar la iglesia. Abandonarla es una solución conveniente para la jerarquía eclesial que sienten que gays y lesbianas solo hacen daño al no seguir las políticas de el Vaticano; si la persona definitivamente se siente perseguida debe considerar el abandono o en si el aislamiento de la institución, parafraseando a McNeill (1998) "una institución que no lo representa"- (p.14), abandonarla puede ser positivo, lo que a la larga ayuda a la persona a experimentar sentimientos de bienestar; Bruguès (2007) destaca que existen otros grupos cristianos de origen católico o protestante que aceptan a la comunidad LGBT dentro de sus congregaciones sin los problemas teológicos que tiene sus contrapartes católicas (p.185).

Lo que sobresale de estas comunidades es que a pesar que usan en la mayor parte de los casos las misma fuentes teológicas, estas no condenan las acciones de las personas LGBT, si no que reafirman su identidad, planteando la posibilidad de que el catolicismo que se inspira en los mismos Evangelios y que además, estructura sus creencias en torno a las leyes naturales, puede modificar sus creencias en torno a las relaciones homosexuales (Kuefler 2005, p. 89).

La realidad es que la situación para hombres y mujeres homosexuales varía de diócesis a arquidiócesis, y de iglesia a parroquia, de acuerdo a las actitudes de los seglares y de los sacerdotes y tiene que ver con factores culturales de la región en la que habitan los individuos de la comunidad LGBT. Un ejemplo claro de la anterior afirmación es que las grandes urbes han sido históricamente de acuerdo a George Chauncey (1994) y John Boswell (1980) los lugares geográficos más incluyentes para los homosexuales, a diferencia de los pequeños núcleos de población rural, esto en alguna medida se debe a que esta población LGTB representa una masa votante que no van a descuidar los planificadores sociales y los políticos en aras de la connotada equidad social. Por otra parte la diversidad de opiniones que se encuentra en las ciudades ofrece varias opciones 
espirituales a los miembros de la comunidad LGBT. Para los que deciden seguir dentro de la iglesia se encuentran algunos sacerdotes que aceptan a las personas con preferencias homosexuales como miembros de su feligresía. La importancia que tiene la tolerancia y el anonimato que se da en las urbes queda demostrado en el sitio de internet de New Ways Ministry que publica un directorio para ayudar a las personas gays a encontrar una parroquia o comunidad católica que sea incluyente para las personas con preferencias homosexuales ${ }^{23}$.

En México no encontramos un directorio de iglesias o comunidades que apoyen a la comunidad LGBT, como lo demuestra una búsqueda rápida en google. com. Si se desea encontrar algún sacerdote que sea amigable o comprensivo de las preferencias homosexuales, la información solo llega por referencia de otras personas que se encuentran en una circunstancia similar. La manera práctica de obtener conocimiento de esta situación es por lo tanto privada, no pública. En este contexto hay información que a veces no es fidedigna y que está inspirada en rumores. Un ejemplo de ello es la creencia que se tiene sobre el rol de determinadas órdenes en la aceptación o el rechazo de las preferencias homosexuales. En México por ejemplo se vislumbra un segmento grande de la Compañía de Jesús que es liberal (Martin 1987 p. 17-9), debido a que persiguen un régimen académico estricto en su formación teologal y esto implicaría, en teoría, que tendrían una actitud tolerante hacia los hombres y mujeres que tienen tratos con ellos. Otras órdenes cuya reputación es buena dentro de la comunidad LGBT son las de los Dominicos y los Oratorianos de San Felipe $\mathrm{Neri}^{24}$, dos órdenes que se considera flexibles cuando administran el sacramento de la penitencia.

Es un hecho que la falta de información implica que las personas que hacen parte de la comunidad LGBT, deben buscar la relación de amistad con miembros de la iglesia que los acepten, aunque ello conlleva implícitamente el riesgo de discriminación por parte de algunas personas o comunidades cuya postura es antagónica hacia la homosexualidad. En Norteamérica han surgido grupos que no se quedan en la búsqueda de aceptación de otros y de la institución de poder católica, sino que están surgiendo movimientos que buscan visibilidad y luchan por pertenecer a una iglesia que los rechaza en principio. Estos grupos se estructuran a un argumento que se basa en el esencialismo. Fox (1995 p. 131), menciona que estos grupos consideran que se nace con ciertos deseos sexuales (p. 131), y se podría remontar de manera accidentada a las ideas de predestinación de San Agustín, lo que es natural en Santo Tomás. Pero esto resulta teleología si lo confrontamos con el aprendizaje social de género y la

Palobra No. 14. Agosto de 2014
${ }^{23}$ Existen algunas páginas web en las que se pueden ubicar las pala comunidad LGBT en ciudades de Canadá y Estados Unidos. Las pá ginas web se encuentran 2008 [21 sept. 2009]): disponible en: http: wWW.newwaysministry.org/GFP.html.

${ }^{24}$ En la ciudad de Puebla el autor puede confirma que durante los ultimos dieciocho años las personas que tenian prefe rencias homosexuales y penitencia podían ir con penitencia podian ir con carisma se conoce popularmente es la confesión. 
${ }^{25}$ [Traducción del autor del presente textol ${ }^{26}[$ Traducción del autor
del presente texto] construcción social identitaria. Si bien es cierto no nacemos siendo católicos, también es cierto que no nacemos siendo heterosexuales.

El grupo que actualmente cuenta con el aval de la jerarquía católica y que tiene representación en varias arquidiócesis de los países norteamericanos es "Courage" que busca transformar las vidas de las personas homosexuales, para ayudarlos a vivir de acuerdo a las creencias de la jerarquía católica. A ontinuación se hace una breve semblanza sobre el grupo.

\section{“Courage"}

T a iglesia católica oficialmente apoya al grupo que tiene la finalidad de "ayudar a las personas" a vivir en castidad. De acuerdo a Tanya Erzen Jen su libro Straight to Jesus (2006) el apoyo que tiene el grupo proviene de algunos miembros de la jerarquía católica que encuentran en este grupo un equilibrio entre la teología católica y el movimiento LGBT.

El 2006 Catholic Almanac define a el grupo "Courage" de la siguiente manera, "ministerio para hombres y mujeres que experimentan atracción homosexual que desean vivir una vida cristiana casta de acuerdo a las enseñanzas de la iglesia católica... El director nacional es el Rev. John F. Harvey (q.e.p.d) ${ }^{25 "}$ (501), quien propuso profundizar en el conocimiento del carisma del grupo. El autor de este artículo realizó dos entrevistas con el organizador del capítulo de "Courage" en la ciudad de Puebla, México, quien tuvo la amabilidad de responder los interrogantes. El propósito principal de "Courage" es ayudar a aquellas personas con tendencias homosexuales a vivir en castidad. Tanya Erzen escribe "Courage se adhiere a la noción católica de que la solución a la homosexualidad es la castidad y la vida comunitaria (p. 46-7) ${ }^{26}$," pero en el año 2008 cuando realicé la primera entrevista, el capítulo de Puebla creía que la homosexualidad era una construcción anormal, y que todos somos heterosexuales. Esta creencia implicaba que a través de un ejercicio complicado se podría regresar a los homosexuales a la heterosexualidad, retomando las ideas de McNeill (1996) sobre la preferencia sexual (p. 66). En la entrevista que realicé en diciembre del 2012, el mismo organizador explicó que: "el movimiento de "Courage" no era un grupo que regresara a las persona a la heterosexualidad, sino que buscaba ayudar a las personas a vivir en castidad, así como a combatir las adicciones a la pornografía, a la masturbación y al sexo con otras personas". Al ser vistas como adicciones las acciones antes mencionadas, deben ser constreñidas para que no causen daño a la persona que las practica. "Courage" canaliza a sus miembros que 
así lo deseen, a ser atendidos por terapeutas que están de acuerdo con los ideales de la organización, a ayudar a las personas a vivir de acuerdo a las enseñanzas de la jerarquía católica.

La meta para algunas de las personas que ingresan a "Courage" es dejar de ser homosexual, y convertirse en alguien "normal" de acuerdo a las enseñanzas del catolicismo (Erzen, 2006 p. 47) ${ }^{27}$. En la entrevista que le realicé al facilitador en el 2008, explicó que las personas eran naturalmente heterosexuales, pero que en algún momento traumático de la infancia se convirtieron en homosexuales. Sostuvo que gracias al grupo y a la terapia él ya se sentía atraído hacia las mujeres. En el 2012, el tema era distinto: "Courage" Puebla ya no ayudaba a la gente a regresar a la heterosexualidad, y de hecho no se hizo una sola mención que el mismo facilitador se encontrara atraído por las mujeres. El movimiento en Puebla ayudaba solamente a luchar contra la sexualidad no reproductiva, y animaba a sus miembros a no identificarse con los ideales de la comunidad gay ${ }^{28}$.

La perspectiva que me narró en el 2008 difería notablemente del discurso del que hablaba en el 2012 y estaba en línea con los postulados del fundador de "Courage" que explicaba:

El propósito entero de los ministerios ex-gay es recuperar la heterosexualidad a través de una relación con Dios, pero el Padre Harvey cree que no hay manera de que una persona elimine las tentaciones, y por lo tanto su meta de vida debe ser vivir una vida casta dentro del cristianismo (Erzen 2006 p. 47) ${ }^{29}$.

El conflicto entre la institución católica y el movimiento LGBT se manifiesta en "Courage" que trata de explicar y organizarse de acuerdo a los lineamientos católicos, que cree que ser gay es una construcción equivocada, aunque como reconoce el facilitador del grupo, el debate sigue en el aire, hasta que no se realicen nuevos descubrimientos que confirme o nieguen lo que origina las preferencias homosexuales ${ }^{30}$.

"Courage" en México tuvo un comienzo accidentado, ya que originalmente fue apoyada por la Legión de Cristo. La orden es considerada de derecha (Berry 1996 p. 243 y Gibson 2003 p. 55) y ha estado envuelta en el escándalo desde el deceso de su fundador, el Padre Marcial Maciel L.C. quien fue acusado por algunos antiguos ex seminaristas ${ }^{31}$ de ser responsable del abuso sexual que padecieron cuando eran niños y adolescentes (Torres Robles 2001 p. 269-
${ }^{27}$ "En el 2008 se destacó: Existe un conflicto en la información que se coordibido ya que el ha informado que e ndividuo podía recuperar su heterosexualidad acción que si postulan vangélicos, pero no é "Covimiento catolico de "courage". "El fundador Harvey, no crela que regresar a la heterosexualidad" era posible: The whole purpose evangelical ex-gay ministries is to recover relationship with $\mathrm{G}$. but Father Harvey believes that there is no way a person will ever eliminate temptations, and is or her goal should "nstead be to live a chaste

${ }^{28}$ Entrevista personal.

${ }^{29}$ [Traducción del autor del presente texto]

${ }^{30}$ Entrevista 2012

${ }^{31}$ Entre los que se destacan Alberto Athié, José Barba y Fernando González por su activismo de la Legión de Cristo como queda constatado en su libro La voluntad de no saber. 
${ }^{32}$ La información fue proporcionada por el facilitador de "Courage" en bre del 2008 . En la últim entrevista que se realizo en diciembre del 2012 con la misma persona, el autor mencionó el nombre de la Legion de Cristo y el facilitador no recordo el nombre de la congre gación. En la actualidac apoyado por el Arzobispo Don Víctor Sánchez y en la página oficial no se menciona a la Legión de Cristo (http://Www. courage-latino.org/cou-

${ }^{33}$ [Mi Traducción]
291). El lenguaje que utiliza la iglesia para igualar a los homosexuales con los pedófilo, expresado en la introducción de este texto (Jordan año p. 94) hizo que la asociación de "Courage" con los Legionarios fuera vista como incómoda para la supervivencia del movimiento ${ }^{32}$.

"Courage" no es visto favorablemente por los activistas de la comunidad LGBT quienes lo categorizan como otro movimiento "ex gay" mas (Erzen 2006 p. 2-3) quienes ven al movimiento católico como un grupo que promueve la heteronormatividad y la homofobia. John McNeill (1996) es sucinto al describir lo que hacen los movimientos ex gay:

Aquellos grupos religiosos que afirman que pueden 'curar' a los homosexuales tratan de hacerlo a través de la intensificación del sentido de culpa que experimentan los hombres gays y las mujeres lesbianas que se consideran pecadores y malos por sus propios sentimientos sexuales. Como la orientación sexual es fundamentalmente inalterable, lo mejor que se puede esperar de este proceso es que la persona gay suprima su identidad gay (p. 66) ${ }^{33}$.

Aunque "Courage" es repulsivo para algunos activistas gay, el movimiento ofrece una presencia a los homosexuales dentro de la institución católica que puede en un futuro servir para abrir diálogos entre católicos y el movimiento LGBT.

\section{Conclusión}

1 lunes 29 de julio del 2013, el recién elegido Papa Francisco I, hizo una pregunta que pudiera indicar que las relaciones entre los distintos grupos gays del mundo y la iglesia católica podrían estar entrando en una nueva fase de relaciones. A una pregunta realizada por algunos periodistas que viajaban con el pontífice de Río de Janeiro a Roma, Francisco I preguntó: "¿quién soy yo para juzgar a los gays?" (“¿Quién soy yo para juzgar a los gays?", cuestiona el papa Francisco." 2013: http://mexico.cnn. com/mundo/2013/07/29/por-que-deberia-juzgar-a-los-gays-cuestiona-elpapa-francisco). La formulación de la respuesta a la pregunta es sorprendente, ya que durante los pontificados de Juan Pablo II y Benedicto XVI, fueron ellos $y$ las distintas oficinas gubernamentales que se encontraban directamente bajo su supervisión, quienes enunciaron una política específica sobre el rol que debía tener la homosexualidad dentro de la iglesia católica y la dirección vaticana era claramente contraria a aceptar un estilo de vida gay dentro de la 
Iglesia. A medida que progrese el papado de Francisco I, podremos ver si hay en realidad una política en la que se contemple una transformación en torno al tema de la homosexualidad, pero en el momento en el que se escribe este artículo, la política sigue siendo oficialmente la misma, como confirmó el Papa en la misma entrevista al afirmar la postura católica frente al matrimonio gay "Todos ustedes conocen perfectamente la posición de la Iglesia sobre ese tema" (CNN México). Mientras las personas LGBT aguardan que los tiempos sean más favorables para su causa desde El Vaticano, sigue habiendo hombres y mujeres con preferencias homosexuales que negocian su relación con la Iglesia. Como se demostró en el artículo Norteamérica parece ser el lugar donde se están gestando grupos que tratan de unir las enseñanzas de los pontífices con una identidad gay, que es una de las características más interesantes del cristianismo norteamericano (Herrero Brasas 2001 p. 187), Lo que resalta es el deseo de grupos de hombres y mujeres que desean seguir siendo parte de la Iglesia; a pesar de que en la tradición católica todas las personas forman parte del cuerpo místico de Dios, muchos abandonaron la institución, por sentir que no podían pertenecer a una asociación que se caracterizaba por un discurso de rechazo a las relaciones sexuales entre personas del mismo sexo, pero aunque parece contradictorio desde una perspectiva de la teoría de la modernidad, es una realidad que hay hombres y mujeres que desean seguir perteneciendo a la iglesia católica y que además están dispuestos a negociar con la institución sobre su felicidad personal. En esta dinámica se incorpora el único movimiento que cuenta con el aval de la institución católica, "Courage", único foro reconocido por la institución católica que les da voz a aquellas personas con preferencias homo-eróticas para hablar, con la condición que sea en los términos que la Iglesia desea. El hecho que la jerarquía apoya a "Courage" no significa, un gran cambio de actitud en la institución, que sigue mostrando a través de su lenguaje, el apoyo a un régimen heteronormativo de la sexualidad. Lo que al parecer tendría mayor impacto en las relaciones entre ambos grupos no se halla en los Evangelios, sino en los avances del conocimiento y en general de la ciencia que ha determinado cuáles son los orígenes de las preferencias homo-eróticas, ahora, si la iglesia acepta o rechaza ciertos rasgos de la cultura LGBT. Hasta ahora el debate continúa y ambos grupos responden representando a sus intereses específicos. 


\section{BIBLIOGRAFÍA}

Audi, R. (1996). The Cambridge dictionary of philosophy. Nueva York, NY. Cambridge University Press.

Berry, J. \& Renner, G. (2004). Vows of silence. The abuse of power in the papacy of John Paul II. Nueva York, Londres, et al.: Free Press.

Blancarte, R. (2004). Entre la fe y el poder. Política y religión en México. México D.F.: Random House Mondadori.

Blancarte, R. (2008). Sexo, religión y democracia. México D.F.: Editorial Planeta Mexicana.

Boswell, J. (1980). Christianity, social tolerance and homosexuality. Gay people in western Europe from the beginning of the christian era to the fourteenth century. Chicago Il: University of Chicago Press.

Bruguès, J., Bedouelle G. \& Becquart, Philippe (2007), La iglesia y la sexualidad. Madrid: Biblioteca de Autores Cristianos.

Bunson M. (2005). 2006 Catholic Almanac. Huntington, IN: Our Sunday Visitor's Publishing Division.

Chauncey, G. (1994). Gay New York. Gender, urban culture, and the making of the gay male world 1890-1940. Nueva York, NY: Basic Books.

Clarke, P. \& Norman, E. (1998). Amor, amor mundi: Augustine and Dante on Will, World and the roots of democracy. Essex: University Of Essex: Department of Government.

Cornwell, J. (2001). Breaking faith. The pope, the people and the fate of catholicism. Nueva York, NY: Viking Compass.

Dignity USA, http://www.dignityusa.org/

Dinshaw, C. (2006). "Touching on the Past," in Mathew Kueflered. The Boswell Thesis. Essays on christianity, social tolerance and homosexuality. Chicago \& London. The University of Chicago Press.

Donadio, Rachel, and Laurie Goodstein. "Vatican bidding anglicans to join its fold. "New York Times (Oct. 20, 2009 [cited 23 Nov. 2009]): available from http://www.nytimes. com/2009/10/21/world/europe/21pope.html

Eribbon, Didier, 1999, Reflexiones sobre la cuestión gay translated in to Spanish by Jaime Zulaika, Editorial Anagrama, Barcelona.

Erzen, Tanya, 2006, Straight to Jesus. Sexual and christian conversions in the Ex-Gay Movement, University of California Press, Berkeley, Los Angeles \& London.

Fausto-Sterling, Anne, 2000, Sexing the body. Gender politics and the construction of sexuality, Basic Books, New York. 
Fazio, Carlos, 2004, En el nombre del padre. Depredadores sexuales de la iglesia, Editorial Océano de México, S.A. de CV., México D.F.

Fone, Byrne, 2000, Homophobia. A history, Picador USA, New York.

Fox, Thomas C, 1995, Sexuality and catholicism. Abortion, homosexuality, women and the church, birth control, clergy and sexual abuse, carnal love, celibacy and population control, George Braziller, New York.

Gardeil, H.D., 1973, Iniciación a la filosofía de Santo Tomas de Aquino. Translated by Salvador Abascal Carranza, Editorial Tradición, México.

Gibson, David, 2003, The coming catholic church. how the faithful are shaping a New American catholicism, Harper San Francisco, New York.

Helminiak, Daniel A., 1995, What the Bible Really says about homosexuality. Recent findings by the top scholars offer a radical new view, Alamo Square Press, San Francisco, CA.

Herrero Brasas, Juan A., 2001, La sociedad gay, Foca ediciones y distribuciones generales S.L., Madrid.

Hogan, Steve and Lee Hudson Completely queer. The Gay and lesbian encyclopedia, Henry Holt \& Co., New York.

Jordan, Mark D, 2000, The silence of Sodom. Homosexuality in modern catholicism, The University of Chicago Press, Chicago\& London.

Kuefler, Mathew, ed., 2006, The boswell thesis. Essays on christianity, social tolerance, and homosexuality, The University of Chicago Press, Chicago\& London.

Levy, Daniel C., and Kathleen Bruhn with Emilio Zebadúa, 2001, Mexico. The struggle for democratic development, University of California Press, Berkeley.

Lugo, Raúl, fecha desconocida, Iglesia Católica y homosexualidad, Editorial Nueva Utopía, Madrid.

Lujan, Néstor and Juan Perucho, 2003, El libro de la cocina española. Gastronomía e historia, Tusquets editores.

Martin, Malachi, 1988, The Jesuits. The society of Jesus and the betrayal of the roman catholic Church, Simon \& Schuster, New York, London et al.

Martin, Thomas F. O.S.A., 2003, Our restless hearts. The augustinian tradition, Orbis Books, New York.

McNeill, Brian Rainbow sash alliance USA ([cited 6 Oct. 2009]): available from www. rainbowsashallainceusa.org

McNeill, John J., 1996. Taking a chance on God, Beacon Press, Boston. 
McNeill, John J., 1988. The church and the homosexual, Beacon Press, Boston.

"¿Quién soy yo para juzgar a los gays?" cuestiona el papa Francisco." CNN México (Jul. 29 1013 [cited 26 Nov. 2013]): available from http://mexico.cnn.com/mundo/2013/07/29/porque-deberia-juzgar-a-los-gays-cuestiona-el-papa-francisco

Rows, A.L., 1977. Homosexuals in history. A study of ambivalence in society, literature and the arts. Dorset Press, USA.

Russell, Bertrand, 1959. Wisdom of the west, Crescent Books, Inc., London.

Schlager, B. (2006). "Reading CSTH as a Call to Action." in Mathew Kueflered. The Boswell Thesis. Essays on christianity, social tolerance, and homosexuality. Chicago \& Londres: University of Chicago press.

Tavis, John. "Clarification on anglicans and married priests. "Catholic News Service (Oct. 31, 2009 [cited 11 Nov. 2009]): available from http://cnsblog.worldpress.com/2009/10/31/clarificationon-anglicans-and-married-priests/

The New American Bible: Official catholic Bible. (1991). Grand Rapids, MI: World Publishing, Grand Rapids.

Torres Robles, A. (2001). La prodigiosa aventura de los Legionarios de Cristo. Madrid: Foca Ediciones.

Venocci, J. "Should Liberals leave the Catholic Church?." Boston Globe (March 5 2006[cited 21 Nov. 2009]): available from http://www.boston.com/news/globe/editorial_opinion/oped/ articles2006/03/05/should_liberals_leave_catholic_church/

Woods, R. (1998). Mysticism and prophecy. The dominican tradition. Londres: Darton, Longman and Todd Ltd. 